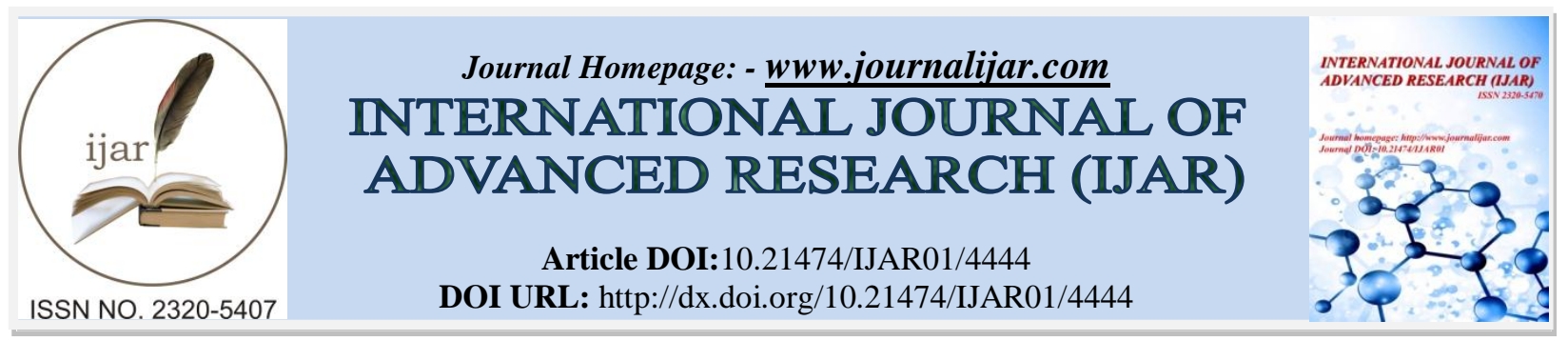

RESEARCH ARTICLE

\title{
ATTITUDE OF SENIOR SECONDARY SCHOOL STUDENTS TOWARDS ALCOHOL AND DRUGS WITH RESPECT TO GENDER, RESIDENTIAL BACKGROUND AND TYPE OF FAMILY.
}

\author{
Mehtab Singh ${ }^{1}$ and Dr. Ram Niwas ${ }^{2}$. \\ 1. Research Scholar, Guru Kashi University, Talwandi Sabo, Bathinda. \\ 2. Assistant Professor, Research Scholar, Guru Kashi University, Talwandi Sabo, Bathinda.
}

\section{Manuscript Info}

..........................

Manuscript History

Received: 11 April 2017

Final Accepted: 13 May 2017

Published: June 2017

Key words:-

Alcohol and Drugs Attitude, Gender, Residence, Rural, Urban, Joint Family, nuclear family, Adolescents.

\section{Abstract}

The present study is aimed to study the Attitude of Senior Secondary School Students with respect to Gender, Residential background and Type of School. Required information was gathered by applying standardized Alcohol and Drug Attitude scale (2010) constructed by Dr. Sandeep Singh and Dr. Sunil Saini on 300 randomly selected Senior Secondary School Students of Government Schools of district Ferozepur of Punjab. The findings of the study are: 1) There exists significant difference in Attitude of Senior Secondary School Students towards Alcohol and Drugs with respect to their Gender. Male Senior Secondary School Students of District Ferozepur are more inclined towards Alcohol and Drugs as compared to females. 2) Significant difference exists in Attitude of Senior Secondary School Students towards Alcohol and Drugs with respect to their Residential Background. It was found that the Senior Secondary School Students of District Ferozepur residing in urban areas have more favourable Attitude towards Alcohol and Drugs as compared to rural area. 3) No significant difference was found in Attitude of Senior Secondary School Students of District Ferozepur towards Alcohol and Drugs with respect to Joint and Nuclear type of families. The investigators concluded that gender differences and residential differences are playing a vital role in determining attitude of adolescents towards alcohol and drugs. A significantly favourable alcohol and drugs attitude of senior secondary school students requires a special attention of society, parents and administration.

Copy Right, IJAR, 2017,. All rights reserved.

\section{Introduction:-}

Education is the process by which individual is encouraged to fully develop his or her potential. The true meaning of education is to teach humans the lesson of humanity and also to make life more developed and cultural. Education is very important for the progress of a person and the society. Education in real sense is to humanize and to make progressive, cultural and civilized Society.

Inspite of increasing literacy rate and transformation of education, there are various problems we are facing. Some of the problems in the society are poverty, population, use of drug and Alcohol, corruption, social and environment 
pollution. Use of drug and alcohol is becoming a serious problem. It is considered as a social problem and it may relate to the attitude of a person towards alcohol and drugs. An attitude can be defined as a favourable or unfavourable evaluation of people, object, event, ideas and activities or just about anything in your environment.

\section{Alcohol and Drugs Attitude:-}

Every person has his/her own attitude and belief about the use and abuse of substances such as illegal drugs, illegal use of prescription drugs, alcohol and tobacco. These attitudes are often deeply held and based on a person's own life history. It is depending on a person's attitude whether drug and alcohol is used or not. If the attitude of a person is positive toward drug and alcohol, then s/he may be a user. But if the attitude of a person is negative towards drug and alcohol then s/he may not using it. The use and misuse of alcohol and drugs is one of the more controversial issues in our society and often a source of conflict between generations and between sections of society. The use of drugs by people can be divided into Recreational drug abusers, Therapeutic drug abusers, Performance enhancing drug abusers and the use of drug to mask the presence of other. Individual drugs cannot be so easily categorized. For example amphetamines, which are commonly referred to as a recreational drug, may be taken as a performance aid by some athletes. The risks involved due to the misuse of drugs, in fact, are plenty that in certain.

\section{Factors Influencing Alcohol and Drug Attitude:-}

In this paper, the researcher attempted to study some possible determiners of attitude like gender, residential background and type of family. As found by Richard W. (2009) high volume drinking were consistently more prevalent among men than among women, but lifetime abstention from alcohol was consistently more prevalent among women. Throughout the world, men are more likely to drink, consume more alcohol, and cause more problems by doing so. This gender gap is one of the few universal gender differences in human social behavior. It is evident in all areas of the world (Almeida-Filho et al., 2004; Degenhardt et al., 1997; McKee et al., 2000; Perdrix et al., 1999; Rijken, Velema, \& Dijkstra, 1998; Sieri et al., 2002), in drinking versus abstinence (Mohan, Chopra, \& Sethi, 2002; Peltzer, 2002), in heavy drinking and intoxication (Gmel, Rehm, \& Kuntsche, 2003; Higuchi et al., 1994; Siegfried et al., 2001), and in alcohol use disorders (Jhingan et al., 2003; Kebede \& Alem, 1999; Yamamoto et al., 1993). The gender gap has varied but persisted for a long time, at least in European history (Martin, 2001) and in the traditions of many pre-industrial societies elsewhere (Willis, 2001).

On the other hand, in case of residential background, Geographic location can be an important factor in determining one's level of risk for alcohol associated problems. Certain factors connecting with living in rural or urban area may increase risk, while others may be protective. For example, the availability of alcohol, norms for acceptable drinking behaviors, demographic characteristics, and economic factors all vary with respect to geographic area and may influence drinking behaviors.

Above all, family is where our roots take hold and grow. In India, the joint family system has been in existence since ancient times. However, with the passage of time, the joint family system has disintegrated, giving rise to the nuclear family system. At present time, family type i.e. joint family and nuclear family work as an important determinant of adolescent's attitude. As found by Chander (2012) drug use is the growing problem among adolescents.

\section{Significance of the Problem:-}

There are different stages of human life like infancy, childhood, adolescence and adulthood. But the most critical stage is the adolescence stage. Nowadays, drugs and alcohol is a major issue in adolescents. Drugs can be both poison and medicine. Most of the people use alcohol and drugs for entertainment and as a status symbol. More probability of this is in adolescence period when parents are not paying proper attention to them. Majority of adolescents taste drugs initially in the bad company which may cause damage for their personal life. They do not think about their future and may spoil their lives. As Sehgal (2016) reported, from a population of approximately 2.77 crore people, around 23 lakhs of people are opioid dependent, around 860,000 people are estimated to be opioid users. In supporting Sehgal, Singh (2016) explored in his study more than 123,000 people are heroin dependent. Over 3.3 lakh addicts were registered for treatment in various de-addiction centres across Punjab from June to December 2015. Drug and alcohol abuse among adolescent students is a major cause for concern. Use of illegal substances may be associated with deterioration in personal and social life, especially in the case of addictive drugs such as heroin when users often become involved in illegal activities to acquire money to purchase the drug (Atkinson RC et al., 2000). 
The present study aimed to investigate the role of gender, residence background and type of family in shaping of attitude of adolescents towards Alcohol and drugs. The results of study suggest about the gender issues related to alcohol and drugs consumption, differences between rural and urban setting and role of nuclear and joint families in alcohol and drugs attitude of adolescents.

\section{Objectives:-}

1. To study the Attitude of Secondary School Students towards Alcohol and Drugs.

2. To find out the difference in Attitude of Senior Secondary School Students towards Alcohol and Drugs with respect to Gender.

3. To find out the difference in Attitude of Senior Secondary School Students towards Alcohol and Drugs with respect to Residential Background.

4. To find out the difference in Attitude of Senior Secondary School Students towards Alcohol and Drugs with respect to family type.

\section{Hypotheses of the Study:-}

1. There exists significant difference in Attitude of Senior Secondary School Students towards Alcohol and Drugs with respect to their Gender.

2. There exists no significant difference in Attitude of Senior Secondary School Students towards Alcohol and Drugs with respect to their Residential Background.

3. There exists no significant difference in Attitude of Senior Secondary School Students towards Alcohol and Drugs with respect to their family type.

\section{Sample:-}

Multistage random sampling technique was used to select the sample for reducing the biasness in the study. All the senior secondary school adolescent students of district Ferozepur of Punjab State is the population of the present study. At first stage, 15 schools were selected randomly from total schools situated in the district. At second stage, students from each school were selected by using again simple random technique. Total 300 students from Senior Secondary Schools were taken from all selected schools belong to urban and rural areas.

\section{Tool Used for the Study:-}

Alcohol and Drug Attitude Scale (2010) constructed by Dr. Sunil Saini and Dr. Sandeep Singh.

\section{Statistical Techniques:-}

- Descriptive analysis was applied to study the distribution of data.

- $\quad t$-test was used to find out the difference between groups.

\section{Delimitations of the study:-}

- $\quad$ The study was delimited to Senior Secondary School Students only.

- The study was confined to district Ferozepur of Punjab State

- The study was delimited with respect to the sample of 300 Senior Secondary School Students.

\section{Analysis and Interpretation:-}

Objective 1:-To study the Attitude of Senior Secondary School Students towards Alcohol and Drugs.

The first objective of the study was to study the Attitude of Senior Secondary School Students towards Alcohol and Drugs. In order to achieve the objective, the mean, standard deviation and percentile were applied.

Table 1:- The Attitude of Senior Secondary School Students Towards Alcohol and Drugs.

\begin{tabular}{|c|c|c|c|}
\hline Levels of Alcohol and Drugs Attitude & Range of Scores & Number of Students & Percentage \\
\hline Positive (Favourable) & $77 \&$ above & 75 & $25 \%$ \\
\hline Average & $76-51$ & 146 & $48.7 \%$ \\
\hline Negative (Unfavourable) & 50 \& below & 79 & $26.3 \%$ \\
\hline
\end{tabular}

$\mathrm{N}=300$

The above table 1 shows the percentile criteria of $\mathrm{P}_{25}$ and $\mathrm{P}_{75}$. The shows the range of score of favourable level of Alcohol and Drugs Attitude is $77 \&$ above $(\mathrm{N}=75)$ and percentage of sample is $25 \%$. Then average level of 
Alcohol and Drugs ranged between 76-51 and $(\mathrm{N}=146)$ percentage of sample in this range is 48.7\%. Moreover, unfavourable level of Alcohol and Drugs Attitude is ranges 50 \& below and $(\mathrm{N}=79)$ percentage of sample is $26.3 \%$.

Table 2:- Showing Group Wise Mean Score of Alcohol and Drug Attitude.

\begin{tabular}{|c|c|c|c|}
\hline Groups & N & Mean & Interpretation \\
\hline All Secondary School Students & 300 & 62.93 & Average \\
\hline Female & 160 & 55.81 & Average \\
\hline Male & 140 & 71.06 & Average \\
\hline Urban & 145 & 65.11 & Average \\
\hline Rural & 155 & 60.89 & Average \\
\hline Nuclear Family & 175 & 62.78 & Average \\
\hline Joint Family & 125 & 63.14 & Average \\
\hline
\end{tabular}

The table 2 illustrates the mean score of all 300 secondary school students regards to the attitude towards alcohol and drugs accounted as 62.93. The mean score of 160 female and 140 male is 55.81 and 71.06, respectively. Moreover, the mean score of 145 urban amounted on 65.11 and of 155 rural is observed to be 60.89. In case of type of families, mean score of 175 adolescents belongs to nuclear family and a joint family is 62.78 and 63.14 , respectively.

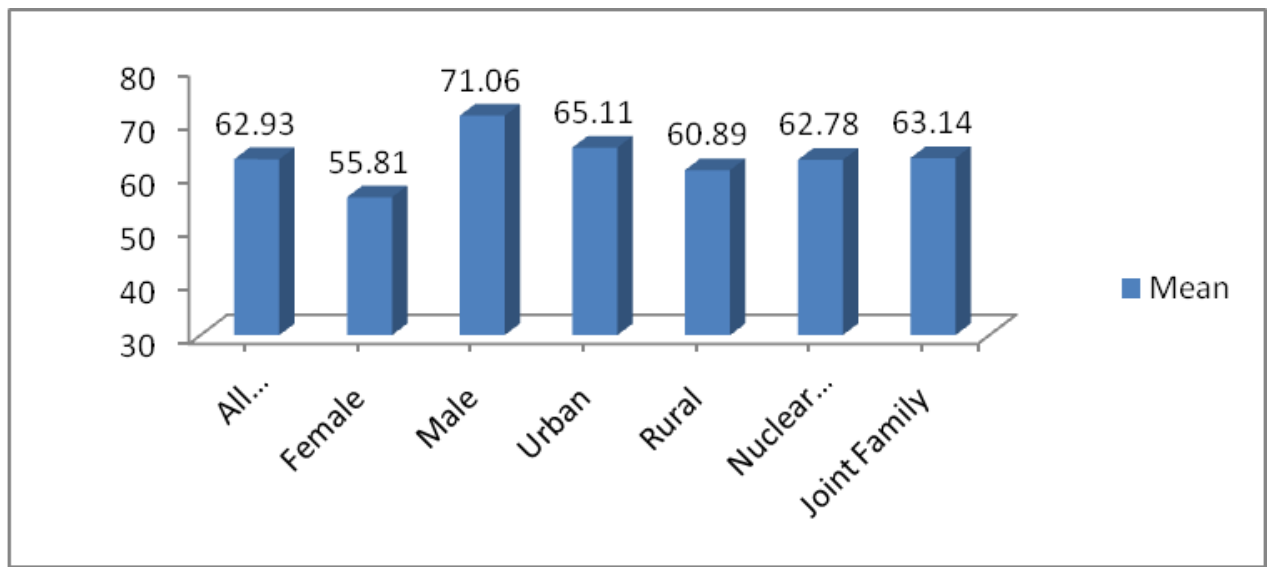

Fig.1:- Showing Group Wise Mean Score of Alcohol and Drug Attitude

The graphical representation the mean score of all 300 secondary school students regards to the attitude towards alcohol and drugs accounted as 62.93. The mean score of 160 female and 140 male is 55.81 and 71.06, respectively. So, male are more likely to indulge in alcohol and drugs. Moreover, the mean score of 145 urban amounted on 65.11 and of 155 rural is observed to be 60.89 , showing higher preference of urban toward alcohol and drugs. The mean score of 62.78 for nuclear family 63.14 for adolescents belongs to joint families.

Hence, the Objective 1: 'To study the Attitude of Senior Secondary School Students towards Alcohol and Drugs' is achieved.

Objective 2:- To find out the difference in Attitude of Senior Secondary School Students towards Alcohol and Drugs with respect to Gender.

The second objective of the study was to find out the difference in Attitude of Senior Secondary School Students towards Alcohol and Drugs with respect to Gender. In order to achieve the objective, the mean, standard deviation and t-value were applied.

Table 3:-Showing the Mean Score, Standard Deviation and t- value of Attitude of Senior Secondary School Students towards Alcohol and Drugs with respect to their Gender

\begin{tabular}{|l|c|c|c|c|c|c|}
\hline Gender & $\mathbf{N}$ & Mean & Std. Deviation & $\mathbf{M}_{\mathbf{D}}$ & $\mathbf{S}_{\mathbf{E}}$ & t value \\
\hline Female & 160 & 55.81 & 12.06 & 15.25 & 1.713 & $\mathbf{8 . 9 0} * *$ \\
\hline
\end{tabular}




\begin{abstract}
\begin{tabular}{l|c|c|c|} 
Male & 140 & 71.06 & 16.84 \\
\hline
\end{tabular}
** Significant at 0.01 level of confidence

The above table 3 illustrates the mean scores, standard deviation and t- value of Attitude of Senior Secondary School Students towards Alcohol and Drugs with respect to their Gender. The table depicts that the mean scores of Alcohol and Drugs in female and male 55.81 and 71.06 respectively. The t-ratio found out to be 8.90 which is higher than the t critical i.e. 2.58 at 0.01 level of confidence. This indicates that the calculated t-ratio is significant at 0.01 level of confidence. The mean scores show that the male senior secondary students have more favourable attitude towards alcohol and drugs as compared to females.
\end{abstract}

Verification of Hypothesis:-

Hence, the hypothesis 1: 'There exists a significant difference in Attitude of Senior Secondary School Students towards Alcohol and Drugs with respect to Gender' is accepted.

\title{
Objective 3:- To find out the difference in Attitude of Senior Secondary School Students towards Alcohol and
} Drugs with respect to Residential Background.

The third objective of the study was to find out the difference in Attitude of Senior Secondary School Students towards Alcohol and Drugs with respect to Residential Background. In order to achieve the objective, the mean, standard deviation and t-test were applied.

Table 4:-Showing the Mean Score, Standard Deviation and t- Value of Attitude of Senior Secondary School Students Towards Alcohol and Drugs With Respect to Residential Background.

\begin{tabular}{|l|c|c|c|c|c|c|}
\hline Residential Background & $\mathbf{N}$ & Mean & Std. Deviation & $\mathbf{M}_{\mathbf{D}}$ & $\mathbf{S}_{\mathbf{E}}$ & t value \\
\hline Urban & 145 & 65.11 & 16.30 & \multirow{2}{*}{4.22} & \multirow{2}{*}{1.876} & \multirow{2}{*}{$\mathbf{2 . 2 5}^{*}$} \\
\hline Rural & 155 & 60.89 & 16.18 & & \\
\hline
\end{tabular}

* Significant at $\mathbf{0 . 0 5}$ level of confidence

The above table 4 illustrates the mean scores, standard deviation and t- value of Attitude of Senior Secondary School Students towards Alcohol and Drugs with respect to their Residential Background. The table depicts that the mean scores of Alcohol and Drugs for Urban and Rural are 65.11 and 60.89, respectively. The t-ratio found out to be 2.25 which is higher than the t-critical i.e. 1.96 at 0.05 level of confidence. This indicates that the calculated t-ratio is significant at 0.05 level of confidence. The mean scores show that the urban senior secondary students have more favourable attitude towards alcohol and drugs as compared to rural senior secondary school students.

\section{Verification of Hypothesis:-}

Hence, the hypothesis 2: 'There exists no significant difference in Attitude of Senior Secondary School Students towards Alcohol and Drugs with respect to Residential Background' is rejected.

Objective 4:- To find out the difference in Attitude of Senior Secondary School Students towards Alcohol and Drugs with respect to family type.

The fourth objective of the study was to find out the difference in Attitude of Senior Secondary School Students towards Alcohol and Drugs with respect to family type. In order to achieve the objective, the mean, standard deviation and t-test were drawn.

Table 5:- Showing the Mean Score, Standard Deviation and t- Value of Attitude of Senior Secondary School Students Towards Alcohol and Drugs With Respect to Family Type

\begin{tabular}{|l|c|c|c|c|c|c|}
\hline Type of Family & $\mathbf{N}$ & Mean & Std. Deviation & $\mathbf{M}_{\mathbf{D}}$ & $\mathbf{S}_{\mathbf{E}}$ & t value \\
\hline Nuclear Family & 175 & 62.78 & 15.80 & 0.35 & \multirow{2}{*}{1.947} & 0.182 \\
\hline Joint Family & 125 & 63.14 & 17.15 & & \\
\hline
\end{tabular}

The above table 5 illustrates the mean scores, standard deviation and t- value of Attitude of Senior Secondary School Students towards Alcohol and Drugs with respect to their family type. The table depicts that the mean scores of Alcohol and Drugs for nuclear family and joint family are 62.78 and 63.14, respectively. The t-ratio was found out to be 0.182 which is lower than the t critical i.e. 1.96 at 0.05 level of confidence. This indicates that the calculated tratio is not significant at 0.05 level of confidence. The mean scores show that the senior secondary students from 
joint families have slightly more but insignificant favourable attitude towards alcohol and drugs as compared to students from nuclear families.

\section{Verification of Hypothesis:-}

Hence, the hypothesis 3: 'There exists no significant difference in Attitude of Senior Secondary School Students towards Alcohol and Drugs with respect to family type' is accepted.

\section{Discussion:-}

The findings of the study shed light on facts that overall senior secondary school students show an average attitude towards alcohol and drugs use which is neither favourable nor unfavourable towards alcohol and drugs use. This outcome may be interpreted as these students are standing on an edge, a little negative stimulus from their environment lead them towards alcohol use whereas slighter efforts and constructive atmosphere may build a strong negative attitude towards alcohol and drugs use. Additionally, high scores of male students in alcohol and drugs attitude than female gender are considerable. The probable ground behind this augmentation is male dominant society where male members enjoy extra liberty, exploration and excessive pocket money etc. This favourable attitude of male students directs them towards substance abuse which can be observed easily in daily news papers. In support Richard W. (2009) found that high volume drinking was consistently more prevalent among men than women. Furthermore in this investigation, area of residence becomes an important point of discussion. In this research it was revealed that students living in urban area showed more favourable attitude towards alcohol and drugs as compared to students reside in rural area. The possible causes of urban students more favourable attitude towards alcohol and drugs are easy availability of substances, more peer interaction, socio-economic status, life style variance etc. Same findings revealed by Negi (2003) prevalence rate of alcohol consumption was $42.2 \%$ in rural area and 55.5\% in urban area. Further Negi found that regular alcohol users were 6\% more in urban area than in rural area. Another finding of the research is that there exists no significant difference in alcohol and drugs attitude among senior secondary school students with respect to type of family i.e. Joint Family and Nuclear Family. It can be interpreted as, the difference in environment and life style of joint family and nuclear family does not impact the alcohol and drugs attitude of senior secondary school students significantly. The above discussion concludes that gender differences and residential differences are playing a vital role in determining attitude of adolescents towards alcohol and drugs. A significantly favourable alcohol and drugs attitude of senior secondary school students requires a special attention of society and administration.

\section{Findings of the Study:-}

* Through obtained mean, it is found that senior secondary school students have an average attitude towards use of alcohol and drugs.

* Through the obtained t-value it is found that there is significant difference on both levels of confidence between senior secondary schools' males and females in relation to alcohol and drugs attitude.

* The mean score of Attitude towards Alcohol and Drugs in males and females was 71.06 and 55.81, respectively.

* The mean score of Attitude towards Alcohol and Drugs in rural and urban senior secondary school students was 60.89 and 65.11 , respectively.

* The obtained $t$ ratio between genders was 8.90 which is higher than $t$ critical i.e. 2.58 at 0.01 level of confidence and showed significant difference between genders at 0.01 level of confidence.

* The obtained $t$ ratio between residential background was 2.25 which is higher than $t$ critical i.e. 1.96 at 0.05 level of confidence and showed significant difference between urban and rural at 0.05 level of confidence.

* The obtained t ratio between nuclear and joint family type was 0.182 which is not significant at any level of confidence and significant difference does not exist between family types.

\section{Conclusions:-}

1. There exists significant difference in Attitude of Senior Secondary School Students towards Alcohol and Drugs with respect to their Gender. Male Senior Secondary School Students of District Ferozepur are more inclined towards alcohol and Drugs attitude as compare to females.

2. The significant difference exists in Attitude of Senior Secondary School Students towards Alcohol and Drugs with respect to their Residential Background. It was found that the Senior Secondary School Students of District Ferozepur residing in urban areas have more favourable Attitude towards Alcohol and Drugs as compare to rural. 
3. The significant difference was not found in Attitude of Senior Secondary School Students of District Ferozepur towards Alcohol and Drugs with respect to Joint and Nuclear type of families.

\section{References:-}

1. Almeida-Filho, N., Lessa, I., Magalhaes, L., Araujo, M. J., Aquino, E. A., Kawachi, I., \& James, S. A. (2004). Alcohol drinking patterns by gender, ethnicity, and social class in Bahia, Brazil. Revista de Saude Publica, 38, 45-54.

2. Atkinson RC, et al. (2000). Hilgard's Introduction to Psychology, 13th ed. London, Harcourt.

3. Chander Subash (2012). Growing problem of drug use among adolescent. Journal of Educational \& Psychological Research, 2(2), 85-86.

4. Degenhardt, L., Hall, W., Teesson, M,; \& Lynskey, M. (1997). Alcohol Use Disorders in Australia: Findings from the National Survey of Mental Health and Well Being. NDARC Technical Report No. 97. National Drug and Alcohol Research Centre, New South Wales, Australia.

5. Gmel, G., Rehm, J., \& Kuntsche, E. (2003). Binge-trinken in Europa: Epidemiologie und folgen. Zeitschrift zur Wissenschaft und Praxis, 49, 105-116.

6. Higuchi, S., Parrish, K. M., Dufour, M. C., Towle, L. H., \& Harford, T. C. (1994). Relationship between age and drinking patterns and drinking problems among Japanese, Japanese-Americans, and Caucasians. Alcoholism: Clinical and Experimental Research, 18, 305-310.

7. Jhingan, H. P., Shyangwa, P., Sharma, A., Prasad, K. M. R., \& Khandelwal, S. K. (2003). Prevalence of alcohol dependence in a town in Nepal as assessed by the CAGE questionnaire. Addiction, 98, 339-343.

8. Kebede, D., \& Alem, A. (1999). The epidemiology of alcohol dependence and problem drinking in Addis Ababa, Ethiopia. Acta Psychiatrica Scandinavica, 100 (Supplement 397), 30-34.

9. Martin, A. L. (2001). Alcohol, Sex, and Gender in Late Medieval and Early Modern Europe. New York: Palgrave

10. McKee, M., Pomerleau, J., Robertson, A., Pudule, I., Grinberga, D., Kadziauskiene, K., Abaravicius, A., \& Vaask, S. (2000). Alcohol consumption in the Baltic Republics. Journal of Epidemiology and Community Health, 54, 361-366.

11. Mohan, D., Chopra, A., \& Sethi, H. (2002). Incidence estimates of substance use disorders in a cohort from Delhi, India. Indian Journal of Medical Research, 115, 128-135.

12. Negi K.S. , Kandpal S.D. and Rawat CMS. (2003). Prevalence of alcoholism among the males in rural and urban area of district dehradun. Indian Journal of Preventive \& Social Medicine,34(3\&4), 85-91.

13. Peltzer, K. (2002). Health behaviour among black and white South Africans. Journal of the Royal Society for the Promotion of Health, 122, 187-193.

14. Perdrix, J., Bovet, P., Larue, D., Yersin, B., Burnand, B., \& Paccaud, F. (1999). Patterns of alcohol consumption in the Seychelles Islands (Indian Ocean). Alcohol and Alcoholism, 34, 773-785.

15. Richard W., Sharon C. Wilsnack, Arlinda F., Kristjanson, Nancy D., Vogeltanz-Holm, and Gerhard Gmel (2009). Gender And Alcohol Consumption: Patterns From The Multinational Genacis Project. Addiction, 104(9): 1487-1500. Doi: 10.1111/j.1360-0443.2009.02696.

16. Rijken, T., Velema, J. P., \& Dijkstra, R. (1998). Alcohol consumption in the rural population of Misungwi subdistrict in Mwanza Region, Tanzania. Journal of Studies on Alcohol, 59, 146-151.

17. Sehgal Rashme (2016). Druggies in punjab spend Rs 2.5 crore a day on drugs. Hindu Jagruti.

18. Siegfried, N., Parry, C. D. H., Morojele, N. K., \& Wason D. (2001). Profile of drinking behaviour and comparison of self-report with the CAGE questionnaire and carbohydrate-deficient transferrin in a rural Lesotho community. Alcohol and Alcoholism, 36, 243-248.

19. Sieri, S., Agudo, A., Kesse, E., Klipstein-Grobusch, K., San-Jose, B., Welch, A. A., Krogh, V., et al . (2002). Patterns of alcohol consumption in 10 European countries participating in the European Prospective Investigation into Cancer and Nutrition (EPIC) project. Public Health Nutrition, 5 (6B) (Special Issue), 12871296.

20. Singh Jupinderjit (2016, April 15) Drug problem in Punjab. The Tribune, p.4

21. Willis, J. (2001). Beer used to belong to older men": Drink and authority among the Nyakyusa of Tanzania. Africa, 71, 373-390.

22. Yamamoto, J., Silva, J. A., Sasao, T., Wang, C., \& Nguyen, L. (1993). Alcoholism in Peru. American Journal of Psychiatry, 150, 1059-1062. 